ERRATUM

doi:10.1038/nature09550

\title{
eIF5 has GDI activity necessary for translational control by eIF2 phosphorylation
}

Martin D. Jennings \& Graham D. Pavitt

Nature 465, 378-381 (2010)

In this Letter, the bar representing the data for Fig. 1c, row 9, was inadvertently deleted. The corrected figure is shown below.

a
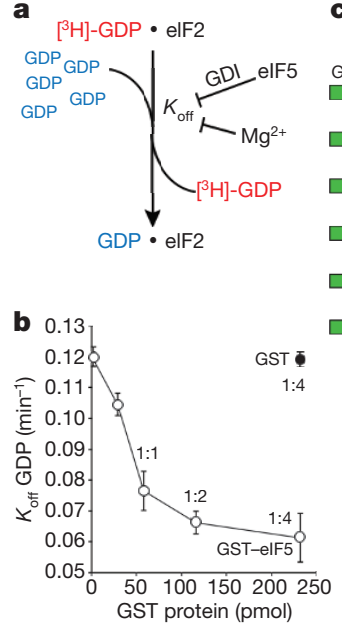

c

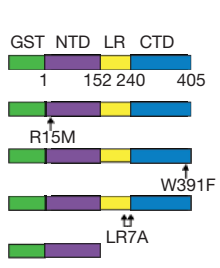

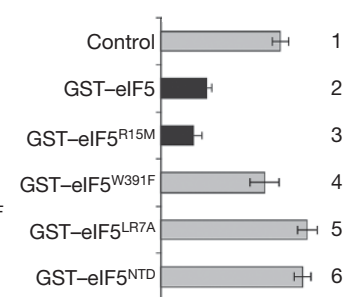

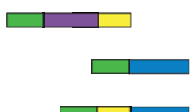

GST-elF5 ${ }^{N T D+L R} \rightarrow 7$

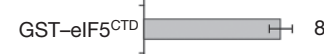

GST-elF5 $5^{\mathrm{LR}+\mathrm{CTD}}$

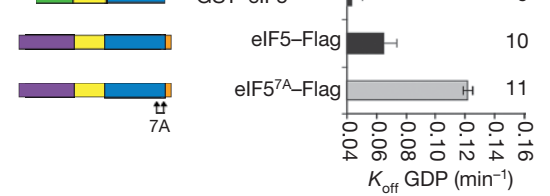

